\title{
PAISAGEM ATRAVÉS DA VÓNILZA OU PAISAGENS DA MEMÓRIA
}

\section{LE PAYSAGE À TRAVERS LA MÉMÉNILZA OU DES PAYSAGES DE LA MÉMOIRE}

\author{
Tiago Radatz Kickhöfel ${ }^{65}$
}

RESUMO: Este ensaio aproxima textos que pensam e expandem o conceito de paisagem a uma relação [afetiva] sujeito-paisagem específica: a experiência da avó do autor no/com o espaço em que vive há quase cem anos. Para a imersão no plano subjetivo desta relação e percepção através de (por meio de), o objeto de aproximação das teorias de pensamentopaisagem (COLLOT, 2014; 2012), de paisagem da memória (BERWANGER DA SILVA, 2012; 2016; COSTA, 2008; MATOLATO, 2007) e de subjetivação perceptiva (JULLIEN, 2009), tomados neste ensaio, utilizou-se a revista literária Vónilza e Tiagua (RADATZ; KICKHÖFEL, 2019), onde o autor desloca os discursos reais da avó para o registro literário. $O$ que o texto busca emergir são os elementos subjetivos de memória, afeto e experiência envolvidos no processo de construção e percepção desta paisagem, o eixo vertical da sua constituição, e as referências teóricas atraídas por este corpus sensível.

Palavras-chave: Paisagem; memória; identidade; experiência.

RÉSUMÉ: Cet essai rassemble des textes qui pensent et développent le concept de paysage à une relation [affective] sujet-paysage particulier : l'expérience de la grand-mère de l'auteur dans/avec l'espace q'elle vit il y a presque cent ans. Pour l'immersion dans le plan subjectif de cette relation et perception à travers de, du objet d'approximation des théories de pensée-paysage (COLLOT, 2014; 2012), la paysage de la mémoire (BERWANGER DA SILVA, 2012; 2016; COSTA, 2008; MATOLATO, 2007) et de la subjectivation perceptive (JULLIEN, 2009), prises dans cet

${ }^{65}$ Mestrando no Programa de Pós-Graduação em Letras, da Universidade Federal do Rio Grande do Sul-PPGL-UFRGS, na linha de pesquisa em Estudos de Literatura, área dos Estudos literários aplicados: literatura, ensino e escrita criativa. Bolsista PROEX - CAPES. 
192 | Tiago Radatz Kickhöfel

essai, s'utilize de le magazine littéraire Vónilza e Tiagua (RADATZ; KICKHÖFEL, 2019), où l'auteur déplace les discours royaux de sa grandmère vers le registre littéraire. Le texte a l'intention de faire émerger les éléments subjectifs de la mémoire, l'affect, et l'expérience qu'ils sont impliqués dans le processus de la construction et perception d'un paysage, l'axe vertical de sa constitution, et les références théoriques attirées par ce corpus sensible.

Mots-clés: Paysage; mémoire; identité; expérience.

\section{"La memoria, esa forma del olvido" El ciego, Jorge Luis Borges}

Este ensaio é uma convergência textual das experiências no "Seminário de Estudos Comparados: Literatura e Paisagem", conduzido pela profa. dra. Maria Luiza Berwanger da Silva. Resulta, portanto, deste "objeto de (ligeiro) delírio", que é o próprio seminário segundo Barthes ${ }^{66}$, no qual coabitam três espaços de maneira simultânea: o institucional - da disciplina do Programa de Pós-Graduação em Letras, na linha de pesquisa em Estudos de Literatura, da Universidade Federal do Rio Grande do Sul; o transferencial - da relação dos participantes do seminário entre si, espaço falansteriano que extenua as opacidades de uma socialidade artificial e trabalha as potências subjetivas dos seminaristas; e o espaço textual - onde são fixados simbolicamente estes entrecruzamentos, como neste ensaio. Destes, é o espaço transferencial que mobiliza a este texto, dado que é a produção das diferenças neste locativo que engendra e justifica a existência do seminário:

A diferença, o que isso quer dizer? Que cada relação, pouco a pouco (isso demanda tempo), se originaliza: reencontra a originalidade dos corpos tomados um a um, quebra a reprodução dos papeis, a repetição dos discursos, elude toda encenação do prestígio, da rivalidade. (BARTHES, 2004, p. 415)

${ }^{66}$ BARTHES, Roland. Au séminaire. In: O rumor da língua. Trad. Leyla Perrone-Moysés et al. São Paulo, 2004. 
E nesta diferença, que concentra e espelha a própria noção de paisagem, ambas definidas sumariamente como zona singular de equilíbrios entre identidades e alteridades, percebi que minha experiência poderia constituir uma abordagem original sobre o assunto do seminário literatura e paisagem. A identidade que me permite tal construção: neto da Vónilza, eco do eco de uma história de imigração, adaptação e resiliência, um produto da confluência entre a sanga e a valeta que por um jogo do acaso deu-se em um acadêmico de Letras, inclinado à escritura e ao deslocamento e que, apesar de ter rompido certa reprodução social, manteve as relações culturais de origem, tanto quanto pôde.

A matéria que ensaio igualmente permite tal deslocamento acadêmico-biográfico, dado que os estudos da paisagem, da zona intermediária entre o espaço subjetivo e o espaço objetivo, só podem ser discutidos sob a valia da experiência, por isso, se desejo pensar e desenvolver o conceito, ele será visto inevitavelmente como fenômeno vivido, como experiência intrínseca de um sujeito e seu ambiente, em um complexo jogo de alteridades, memória, espaço e tempo.

Por que então a senhora Nilza Stein Radatz (Vónilza) estaria neste espaço privilegiado de percepção da paisagem? Porque ela constitui um fenômeno identitário raro em nossos dias: é uma senhora de 98 anos de idade, filha de imigrantes alemães fugidos da I Guerra, que desde que casou, aos 19 anos de idade (e tão logo enviuvou), vive na mesma casa feita do barro daquela terra que lhe coube (no município de Canguçu, no extremo Sul do Brasil), do qual ela parece ter sido moldada junto, visto que casa e avó às vezes se confundem, pois nunca houve uma sem a outra. Ao contrário da maioria das pessoas que foram várias ao longo da vida, Vónilza não foi muitas, seu espaço de ação e afeto, desde o começo da lida adulta, concentrou-se naquela paisagem, de tal modo que o olhar, o pensamento espacialmente imediato e o conhecimento orgânico dos fenômenos ali recorrentes tornam nítidas as relações sujeito-paisagem, evidenciando que

a paisagem não é um puro objeto em face do qual o sujeito poderá se situar numa relação de exterioridade, ela se revela numa experiência em que sujeito e objeto são inseparáveis, não somente porque o objeto espacial é constituído pelo sujeito, mas também porque o sujeito, por sua vez, encontra-se englobado pelo espaço. (COLLOT, 2014, pp. 18-19) 
De tal modo que ela, este sujeito perceptivo, não é espectadora externa da paisagem, antes a compõe, pois percebe a si ao mesmo tempo em que percebe o ambiente neste fenômeno de interação. Tal experiência no espaço intersticial da relação mundo-sujeito faz desta não uma oposição, "mas um encontro e uma interação permanente entre o dentro e o fora, o eu e o outro" (COLLOT, 2014, p. 26), sem hierarquia, objetificação ou passividade, mas latência.

Michel Collot irá contribuir sobremaneira com estes estudos que percebem a paisagem como fruto de influências mútuas entre $\mathrm{o}$ sensibilizado e o que sensibiliza ao observar a mediação do olhar neste processo, ao mesmo tempo, como um "ato estético" e um "ato do pensamento". Assim, para gerar o sintagma "pensamento-paisagem”, desconstrói a lógica binária do sujeito-objeto, que percebe a paisagem numa relação de sentido único, ao sugerir que "a paisagem provoca o pensar e que o pensamento se desdobra como paisagem" (COLLOT, 2013, p.12). Tal sintagma assume um procedimento capaz de transformar as experiências do ver, do fazer e do pensar em experiências sensíveis, ou nos termos do autor, em "atividades sintéticas" dos elementos que se unem em dada paisagem, fazendo com que um elemento não seja percebido se não em suas relações com outros no interior do campo sensível; e assim temos a percepção como forma de pensamento préreflexivo, intuitivo, que por meio de outros sentidos enriquece a dimensão subjetiva do espaço enquanto experiência.

Berwanger da Silva (2013), ao traduzir a obra do filósofo francês François Jullien, Les transformations silencieuses (2009), percebe que o pensamento do autor sobre a experiência subjetiva na paisagem, $\mathrm{o}$ conceito viver de paisagem ("viure de paysage"), converge com o de Michel Collot inscrito no sintagma pensamento-paisagem, onde a representação é substituída pela presença, somando ao fenômeno a "transformação silenciosa" efetuada pelo sujeito na experiência paisagística que transforma esta relação de perceptiva à afetiva.

Estando o sujeito, deste modo, em um processo de subjetivação com a paisagem a partir de sua percepção afetiva, e assumindo a perspectiva de que "o mundo está ao meu redor, não diante de mim" (Merleau-Ponty), tomarei como referente deste diálogo sujeito-mundo, para dar sentido material ao estudo, a revista literária que compus sobre os discursos da Vónilza, Vónilza e Tiagua, no prelo pela editora independente portoalegrense Guaipeca. Nesta publicação, os discursos e pensamentos externalizados pela Vónilza, gravados por mim em conversas 
ao lado do fogão à lenha ao longo dos últimos quatro anos, foram selecionados, versificados e arranjados pela linguagem literária através da técnica ready-made ${ }^{67}$, sendo possível uma internalização maior no referente subjetivo deste estudo, envolvido na decifração daquela paisagem.

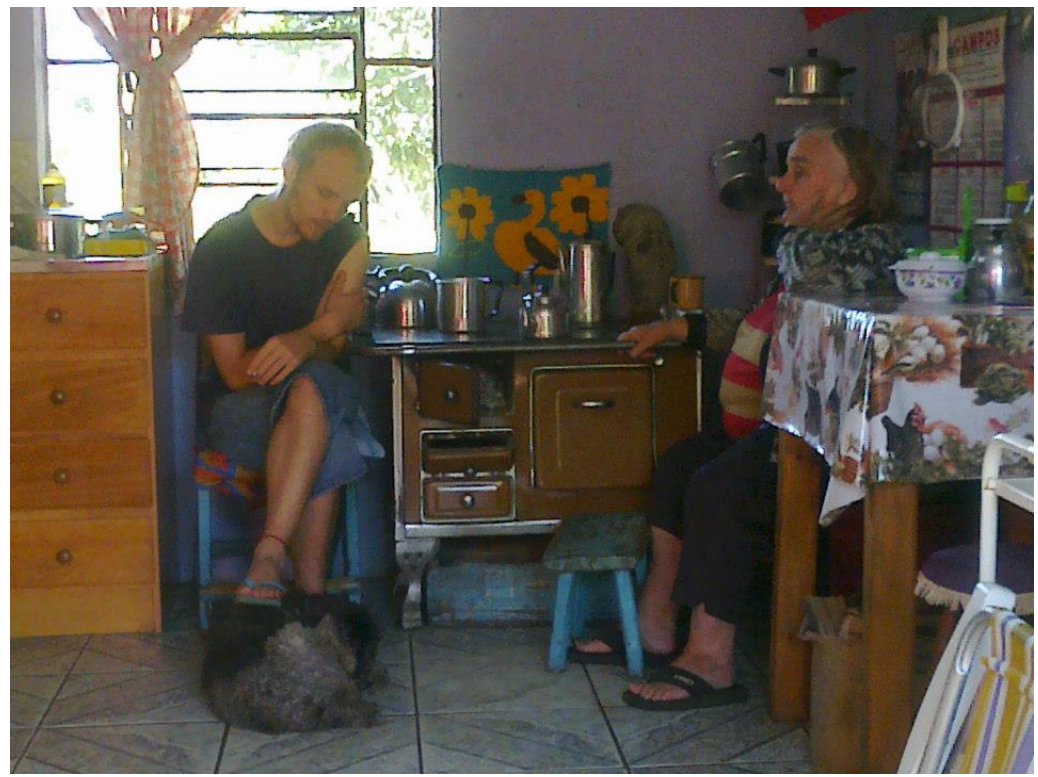

Figura 1. Registro do ato. Tiagua e Vónilza. Foto: Bruno S. Ranzani da Silva, 2015

Este material parte de um percurso de deslocamentos para sua composição: da percepção para a experiência, do discurso cotidiano para

${ }^{67}$ Procedimento de criação artística surgido no período das vanguardas do início do século XX; trata-se do deslocamento de discursos reais - e geralmente banais - e um registro distinto, subvertendo ou corrompendo seu significado e gerando metáforas polissêmicas. Marcel Duchamp inaugura o procedimento nas artes plásticas com as icônicas instalações "Roda de bicicleta" (1913) e "Fonte" (1917) e, trazido à literatura, desde o modernismo aparece como método de criação poética, de Oswald de Andrade (Revista de Antropofagia n.1, coluna Brasiliana, maio de 1928) à Stela do Patrocínio (Reino dos bichos e dos animais é o meu nome, org. Viviane Mosé, 2001) este, um dos resultados mais poderosos da técnica na literatura contemporânea. 


\section{6 | Tiago Radatz Kickhöfel}

o literário, da avó para o neto, do neto para o autor, de mim para o outro; também aí a convergência com os estudos da paisagem é perceptiva, pois esta se forma no deslocamento de um olhar obtuso no entrecruzamento do tempo e do espaço dotado de uma função exploratória: a poeticidade intrínseca de uma subjetividade em relação simbiótica com seu espaço.

Formalmente, a publicação Vónilza e Tiagua contém duas partes, a primeira apresenta uma série de reproduções dos bordados da Vónilza, cujas formas são reflexos diretos da interação com o espaço que habita e uma atividade psíquica/mnemônica comprometida, desgastada pelo quase século de uso; e a segunda parte apresenta três séries de poemas: "da janela", "da mesa" e "do fogão", trazidos dos discursos cotidianos diretos da Sra. Nilza acerca dos três conjuntos que orbitam seu campo de visão imediato, a partir do seu lugar de repouso diário; discursos estes que não seguem uma linha temporal, onde passado e presente são sobrepostos e impressos simultaneamente na memória destes três conjuntos-paisagens. A apresentação da revista explica um pouco seu conteúdo, construção e autoria:

Vónilza é uma tartaruga que hoje tem 98 anos, ontem disse que tinha 50 e no sábado levou suas gêmeas (Zilma \& Zilda, as Irmãs Radatz, que em 1966 foram coroadas Miss Canguçu juntas) pra praia de São Lourenço.

Vónilza é uma tartaruga de barro, como a casa que mora desde que casou e tão logo enviuvou. O vô pra nós é a mesa feita por ele onde ela apoia o braço esquerdo nas tardes ao lado do fogão, ora olhando faustão (televisão), ora a janela com vista pra estrada, pouco antes do cerro.

Vónilza é uma tartaruga de barro e faz bordados, com a mobilidade e a memória de uma tartaruga de barro bordadeira, isto é, esquecendo o que estava fazendo e logo seguindo a lembrança que, nem sempre, corresponde ao trabalho interrompido. "Tudo de cabeça".

Vónilza é uma tartaruga de barro que faz bordados e leva as duas mãos no rosto quando me vê fazendo coisas com a mão esquerda.

Tiagua é um neto da Vónilza. 
Assim, a memória, este elemento fundamental na significação da paisagem, "binómio inseparável, de total complementaridade, cuja construção corre em paralelo" (MATALOTO, 2007, p.124), ao sobrepor dados temporais na paisagem a altera e cria uma realidade outra, uma terceira paisagem, não menos real, que não é a que vejo, ou a que ela vê, mas a que ela significa a partir de sua memória, que guia a percepção e forma sua identidade. É certo que nenhuma paisagem é decodificada da mesma forma, pois o eixo vertical de sua constituição (a subjetividade do ponto de vista) não se repete, o que evidencio aqui é uma construção/significação da mesma paisagem de modos diferentes pelo mesmo sujeito, no mesmo ponto de vista, porém, "a memória, esta forma do esquecimento", é quem seleciona distintos referentes temporais de leitura, formando distintas "paisagens da memória". Por exemplo, o poema III "da janela" mostra, no mínimo, duas linhas temporais e duas paisagens simultâneas, a do presente imediato e de um passado presentificado:

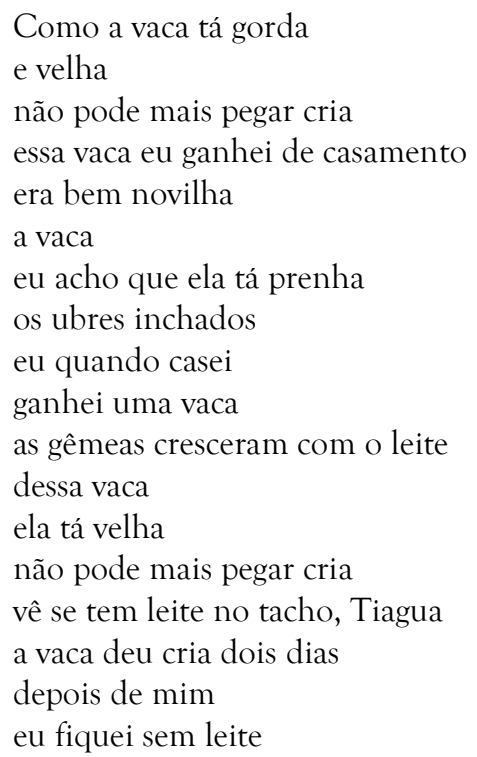

É nesta experiência mnemônica da(s) paisagem(ns), isto é, na construção e compartilhamento de uma paisagem, que surge a noção de identidade enquanto sentimento de pertença, a assimilação de si no 
espaço e do espaço em si. E a vaca gorda e velha é emoldurada por algo além da janela, por uma memória tomada de consciência de ações cognoscentes da gravidez, do mamífero, do fêmeo, que a espelha, e cujo referente temporal se desloca, envolvendo uma série de elementos e signos no espaço afetivo de percepção. Segundo Rui Matolato,

a relação entre paisagem e memória está assentada na geografia da percepção, na existência de um conjunto de signos que estruturam a paisagem segundo o próprio sujeito e refletindo uma composição mental resultante de uma seleção plena de subjetividade a partir da informação emitida por seu entorno. (2007, p. 125)

Desta forma, concordando com o autor supracitado, é possível admitir que a construção da paisagem não se dá apenas pela inclusão ou transformação de elementos ou conjuntos externos, fisiográficos, mas sobretudo por novas percepções e concepções do sujeito envolvido, que provocam uma nova semântica da paisagem: "Assim, a sua profunda transformação poderá ser gerada sem uma alteração radical do contexto físico e material das pré-existências, 'apenas' com a sua reconceptualização” (MATOLATO, 2007, p. 124).

Temos visto que a presença, "a experiência paisagística da presença”, é um elemento de substituição da representação da paisagem, pois esta nunca é reprodução, nunca somente uma imagem estática, pois tal seria uma paisagem desprovida de pensamento, inconcebível sendo esta fruto de uma experiência sensível guiada pela percepção: "longe de ficar estática como uma imagem, a paisagem é um espaço a percorrer, a pé, num veículo ou em sonho" (COLLOT, 2013, p. 52). A "ótica ecológica" que atua na construção da paisagem pressupõe a presença de um corpo e um olhar sensibilizados, pois, como afirma a professora Maria Luiza Berwanger da Silva, a percepção presentificada participa efetivamente na significação da paisagem:

Percepção ampla que, uma vez relocalizada no presente, incidirá na revalorização do fora (ou do dehors) como ponto de equilíbrio entre o coletivo e o privado e perspectiva da qual a certeza neste intermezzo (in el mezzo del camino, o antecipava Dante) garante a prática da constante oscilação entre um e outro (ou outros espaços); esta percepção paisagística funda territórios de confluência nos quais todo 
Paisagem através da Vónilza ou paisagens da memória | 199

dom, dom do olhar, produz na troca, troca de olhares, de figurações e, pois, de difrações do sentimento de paisagem (BERWANGER DA SILVA, 2012, p. 117).

Pois a paisagem é um fenômeno, um conjunto dinâmico de símbolos com o qual o sujeito se relaciona, significa e é significado, de modo a não poder ser considerada de maneira isolada, dissociada do sujeito que a experimenta. Paisagem é, portanto, a experiência subjetiva de um fenômeno paisagístico. Segundo Yi-Fu Tuan (1983, p. 7), na paisagem "a amplitude da experiência ou conhecimento pode ser direta e íntima, ou pode ser indireta e conceitual, mediada por símbolos"; Vónilza, por ser há tanto (n)aquela paisagem, possui o conhecimento empírico dos fenômenos circundantes, o que lhe permite a leitura dos seus símbolos naturalmente. No primeiro poema do conjunto "da janela", a mudança climática é prevista através dos símbolos que ela significa daquele ponto de vista (no horizonte, o cerro coberto de neblina, na paisagem sonora, o canto diferente do bem-te-vi, no terreno, as formigas com asas anunciam a chuva).

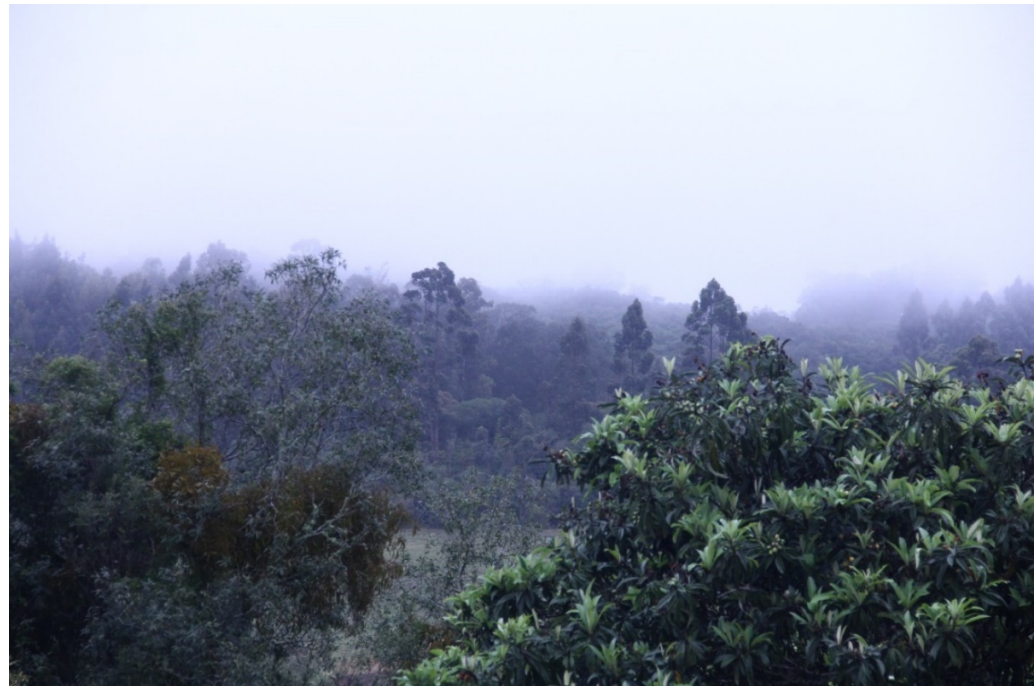

Figura 2. Representação da paisagem. Foto: Tiago R. Kickhöfel, 2015 
200 | Tiago Radatz Kickhöfel

clareou o cerro

clareou o cerro

zilma, a roupa

clareou o

cerro

viu, tiagua

tu tem vista boa

vê se tem formiga

com asa lá fora

clareou o cerro

ouviu o bem-te-vi diferente

clareou o cerro ó

bem-te-vi

clareou o cerro

desliga o faustão da tomada

recolhe a vaca, zilma, a roupa

Aqui há uma evidência da coexistência paisagem-sujeito, pois a avó também se torna símbolo e emite sinais referentes à leitura climática da paisagem por meio de seus rituais: desligar a televisão, recolher a vaca à cocheira e a roupa do varal - e outros inevidentes no poema. Portanto, como aponta Costa (2008, p.2), “os saberes e fazeres humanos atribuem significados e organizam as paisagens e os símbolos presentes fazem a mediação entre o mundo interior e o mundo exterior”. Esta noção corrobora com o pensamento de Collot ao apontar a organização 
perceptiva não limitada ao material fornecido pelo espaço isoladamente, pois cada símbolo é percebido e interpretado em função do seu contexto, daí a noção do autor de "visão de conjunto". Assim "A chuva é algo além de uma precipitação de água [...] porque ela é inseparável de todo um mundo de sensações, de emoções, de evocações, cujo encadeamento mais ou menos codificado a insere numa certa paisagem". (COLLOT, 2013, p. 28 apud BERQUE)

Nos bordados da Vónilza que figuram na primeira parte da revista, os símbolos da sua paisagem são significados e transformados em ícones figurativos que expressam tanto a subjetivação afetiva do espaço, quanto à construção de uma memória do lugar, tornando-se uma espécie de espelho simbólico deste processo psíquico. Por exemplo, o primeiro destes bordados, com o qual fui presenteado como lembrança do sítio quando de minha mudança para Porto Alegre, forma um ser híbrido entre a vaca, o cabrito e o cachorro do sítio; porém, no horizonte semântico envolvido neste processo de criação estava a minha relação afetiva com os animais daquela paisagem, e era com esta relação que sua memória estava comprometida. Assim, passou de um animal a outro conforme compunha o desenho, sem perda ou corrupção deste horizonte, e sem que percebesse o processo.

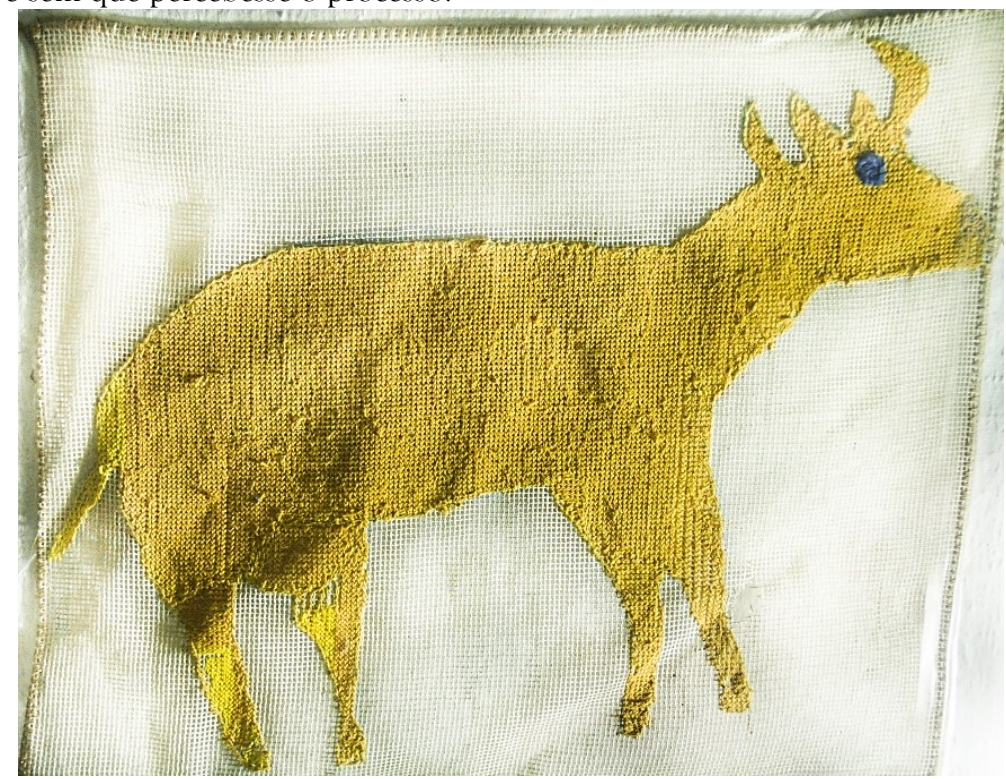

Figura 3. Bordado n.1. Nilza Stein, 2018 
O bordado agora compõe uma nova paisagem, exposto no meu quarto, em contraste com os sons de trânsito do centro da capital gaúcha, pois sua paisagem semântica ultrapassa as linhas amarelas e é representação de puro afeto do meu pago, cujo som de nada lembra este. Como este bordado, outras figurações dos símbolos e ações da paisagem foram ressignificados por discursos verbais e icônicos da Vónilza, a principal constituinte e espelho daquela paisagem, e decifrá-los é como dividir com ela sua experiência de "viver de paisagem".

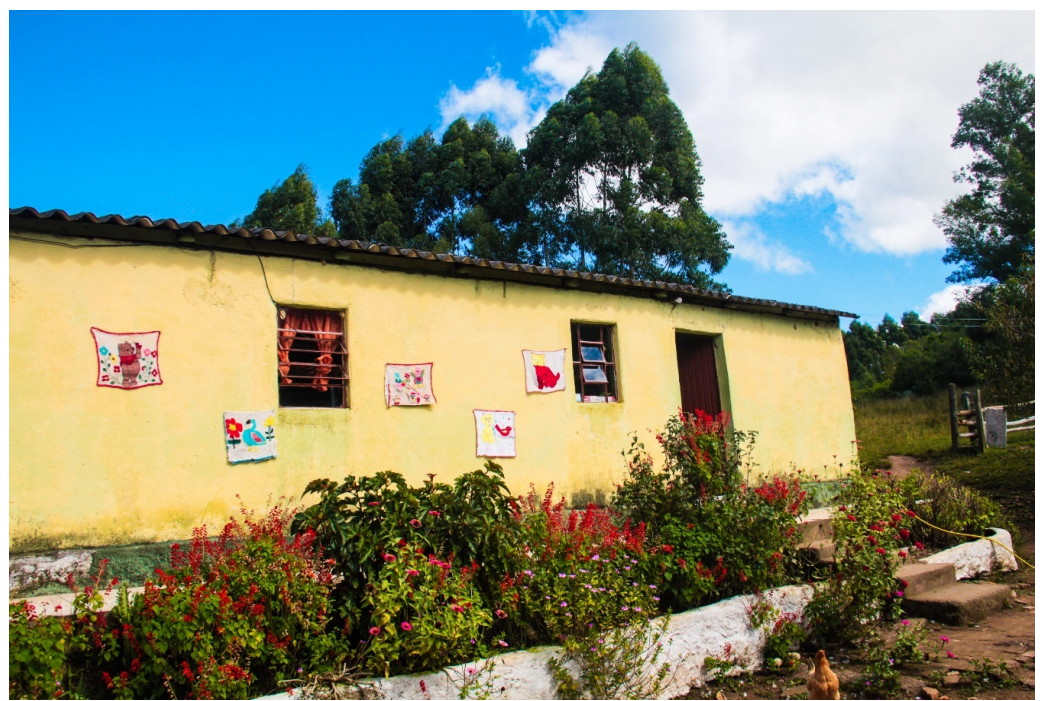

Figura 4. Exposição de bordados da Vónilza à paisagem. Foto: Tiago R. Kickhöfel, 2019

\section{Conclusões}

Os estudos sobre paisagem vistos pela geografia humana é campo produtivo que contribui sobremaneira com as pesquisas sobre processos de subjetivação, identidade, alteridade e outros fenômenos de constituição do sujeito em relação afetiva com o espaço circundante, que transborda para as mais diversas áreas do conhecimento que tratam dessas questões, como a literatura, o urbanismo e a sociologia. Ao perceber o eixo vertical (a subjetividade) como essencial na significação da paisagem, todo um escopo de inevidências se apresenta, sobretudo a noção central de que o sujeito, ao mesmo tempo em que constrói a paisagem, por ela é 
construído, de tal modo que qualquer hierarquia é invalidade pelo sujeito-paisagem, fazendo dela não uma representação externa do espaço, mas uma experiência íntima. $O$ estudo apontou que a mediação simbólica desta relação transforma o próprio sujeito em símbolo significante, à exemplo da avó que, por meio de seus rituais, também premedita a chuva, e das próprias poesias transcriadas, pois como afirma Michel Collot, o poema não é uma textualidade fechada em si, mas se constitui como poema exatamente pela abertura ao além de si. "A textualidade do poema reenvia a textura do universo", dado que "o poema faz ver o mundo na medida em que é ele próprio um mundo que se faz ver." (COLLOT, 2005 , p. 178). Outro ponto crucial nos estudos de paisagem é a formação da identidade por meio da memória do espaço, que participa ativamente na construção da paisagem e produz o sentimento de pertença, onde sujeito e espaço mutuamente são assimilados. Por fim, o que considero mais relevante nos estudos contemporâneos sobre paisagem é a possibilidade que ela engendra de participação de sujeitos geralmente à margem da pesquisa, pondo-os no centro de interesse e validando-os como agentes ativos no processo de construção de conhecimento, tornando pertinente, por exemplo, este estudo da Paisagem através da Vónilza.

\section{REFERÊNCIAS}

ALVES, I. Em torno da paisagem: literatura e geografia em diálogo interdisciplinar. Revista da Anpoll, v. 1, n. 35, pp. 181-202, 2013.

BERWANGER DA SILVA, M. L. Poesia brasileira contemporânea, paisagem e memória. In: Organon, Porto Alegre, v. 31, n. 61, pp. 65-80, jul/dez. 2016.

BERWANGER DA SILVA, M. L. Paisagem e alteridade: o dom e a troca. Literatura e paisagem em diálogo. In: NEGREIROS, C.; LEMOS, M.; ALVES, I. (orgs.). Rio de Janeiro: Edições Makunaima, 2012.

CABRAL, L. O. A paisagem enquanto fenômeno vivido. Geosul, v. 15, n. 30, pp. 34-45, 2000.

COLLOT, M. Pontos de vista sobre a percepção de paisagens. Tradução de Denise Grimm. Literatura e paisagem em diálogo. In: NEGREIROS, C.; LEMOS, M.; ALVES, I. (orgs.). Rio de Janeiro: Edições Makunaima, 2012. 


\section{4 | Tiago Radatz Kickhöfel}

COLlOT, M. et al. Poética e filosofia da paisagem. Rio de Janeiro: Oficina Raquel, 2014.

COLlOT, M. Paysage et poésie: du romantisme à nos jours. José Corti Editions, 2005.

COSTA, O. Memória e Paisagem: em busca do simbólico dos lugares. In: Espaço e cultura, pp. 149-156, 2008.

JULLIEN, F. Les transformations silencieuses. Paris: Grasset, 2009.

RADATZ, N. S. Vónilza e Tiagua. KICKHÖFEL, T. R. (org.). Guaipeca edições: Porto Alegre, 2019.

TUAN, Y-F. Espaço e lugar: a perspectiva da experiência/tradução de Livia de Oliveira. São Paulo: DIFEL, 1983.

Recebido em: 25/08/2019

Aceito em: 15/09/2019 